Annales Geophysicae (2002) 20: 93-106 (C) European Geophysical Society 2002

\title{
A deep cyclone of African origin over the Western Mediterranean: diagnosis and numerical simulation
}

\author{
V. Homar ${ }^{1}$, C. Ramis ${ }^{1}$, and S. Alonso ${ }^{1,2}$ \\ ${ }^{1}$ Meteorology Group, Dept. de Física, Univ. de les Illes Balears, Palma de Mallorca, Spain \\ ${ }^{2}$ IMEDEA, UIB-CSIC, Palma de Mallorca, Spain
}

Received: 26 January 2001 - Revised: 16 June 2001 - Accepted: 25 June 2001

\begin{abstract}
From 19 to 22 December 1979, a deep cyclone evolved over the Western Mediterranean. Gusty winds of more than $30 \mathrm{~m} / \mathrm{s}$, as well as a strong pressure decrease to about $990 \mathrm{hPa}$ were recorded in Palma de Mallorca (Balearic Islands, Spain). ECMWF analyses are used for a diagnosis and numerical study of the case. Sensitivity experiments using the HIRLAM model are performed to assess the role of the surface sensible heat flux, latent heat release and orography on the genesis and evolution of the cyclone. At synoptic scale, the situation is governed by the instability of an upperlevel short wave. The cyclone developed within a notable baroclinic environment, which resulted from a cold advection from the northwest towards North Africa. The baroclinicity at first stages of the cyclogenesis is quantified by means of the Eady model. At latter stages, the evolution of the potential vorticity structures at high levels reveals a wide tropopause fold over the cyclone, as well as the presence of a strong anomaly associated with the low-level system. Sensitivity experiments reveal a notable cyclogenetic role of the latent heat release throughout the atmosphere in the deepening of the low, whereas no significant effect of the surface sensible heat flux is obtained for the simulation interval. On the other hand, an unusual cyclolytic role can be attributed to the northern ranges of the Mediterranean basin. Effectively, the low enlargement and deepening is constrained by a "wall effect", which is a consequence of the interaction of the cyclonic flow and those northern mountainous systems.
\end{abstract}

Key words. Meteorology and atmospheric dynamics (synoptic-scale meteorology, Mesoscale meteorology)

\section{Introduction}

A rapidly deepening cyclone caused strong gusty winds over the eastern and northern coasts of the Balearic Islands (see Fig. 1 for all the locations referred to in the text) between 20 and 22 December 1979. Some damage occurred in the

Correspondence to: V. Homar (victor.homar@uib.es)
Balearics, with many trees uprooted, and some seashore buildings affected. The meteorological station at Palma de Mallorca recorded sustained winds stronger than $10 \mathrm{~m} / \mathrm{s}$ during more than 78 hours and some gusts exceeding $30 \mathrm{~m} / \mathrm{s}$. A notable surface pressure fall was also recorded at Palma de Mallorca, with a decrease of $35 \mathrm{hPa}$ in 60 hours. The ECMWF reanalysis shows a strong, sudden deepening of the cyclone over North Africa which moved northwards over the Mediterranean, to east of the Balearics.

Even if we consider the various and complex cyclogenetic mechanisms which have been said to occur in the Mediterranean basin (e.g. Reiter, 1975; Alpert et al., 1990), such rapidly deepening African cyclones moving northwards are unusual (Conte et al., 1997). In the Western Mediterranean, the Alps, Pyrenees and Atlas ranges are well-known as cyclogenetic systems when they interact with particular synoptic flows. Buzzi and Tibaldi (1978) studied the role of the alpine range on the Genoa Gulf cyclogenesis; the role of the Pyrenees on the genesis of a surface pressure dipole was pointed out by Bessemoulin et al. (1993); and the modification of the mesoscale circulation by the Algerian Atlas range, favouring the heavy precipitation events in Eastern Spain, has been discussed by Romero et al. (1997) and Homar et al. (1999).

The effects of the upper-level dynamics on the surface cyclogenesis has been widely studied and assessed from the potential vorticity (PV) point of view. Although this approach adds no physics to the traditional way of thinking, the PV framework makes the analysis and interpretation of the synoptic dynamics much easier (Raymond, 1992). High tropospheric PV anomalies and their advection are known to influence low-level dynamics (Hoskins et al., 1985). In particular, advection of positive $\mathrm{PV}$ anomalies at upper-levels forces cyclogenesis at low-levels.

Sanders and Gyakum (1980) performed a climatological study from a large number of very quickly deepening cyclones (inappropriately called meteorological "bombs" by the authors, in our opinion) observed in the Northern Hemisphere. They are characterized by a deepening of more than 1 Bergeron, defined as the deepening of the central pressure 


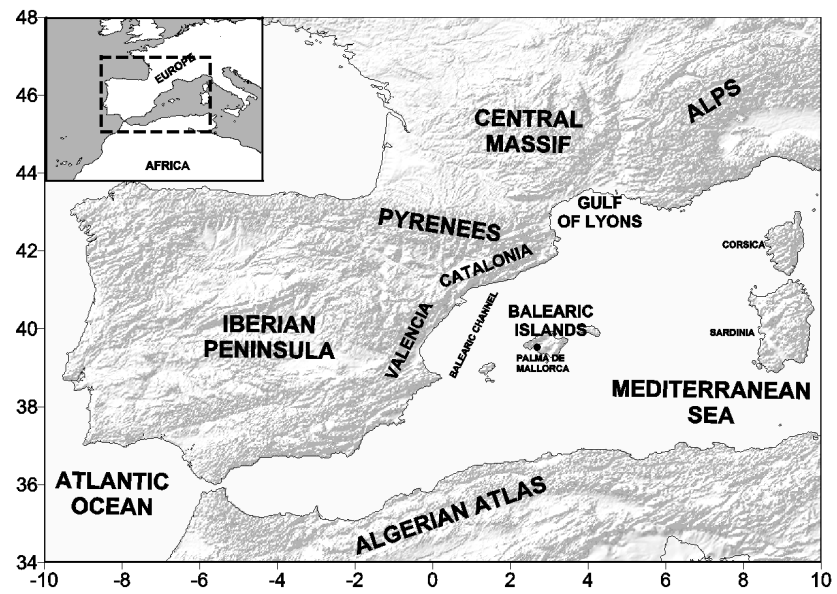

Fig. 1. Western Mediterranean Area. The map includes locations referred to in the text.

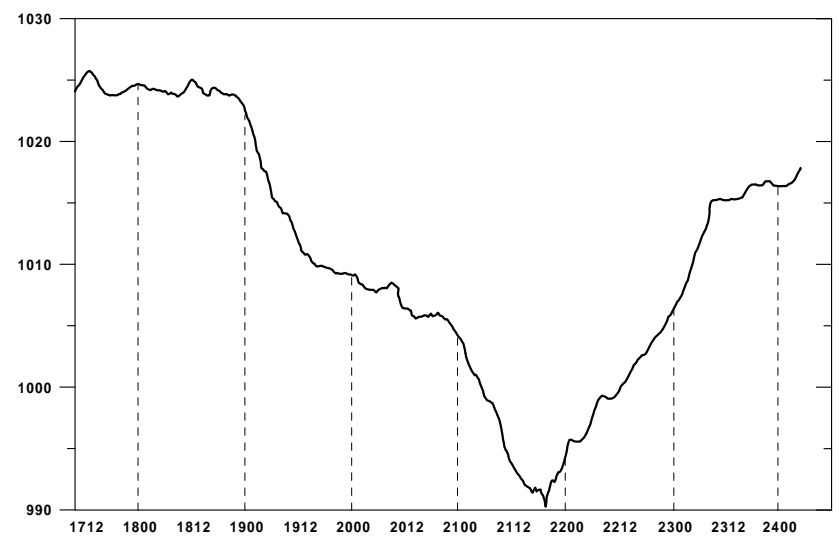

Fig. 2. Surface Pressure (hPa) evolution as recorded at the Palma station for the period from 17 to 24 December 1979. Date labels are presented in DDHH format. Dashed lines show midnight times.

of extra-tropical lows at a rate of $1 \mathrm{hPah}^{-1}$ during $24 \mathrm{~h}$ at $60^{\circ} \mathrm{N}$. At any other latitude, the Bergeron is redefined as its geostrophic equivalent, i.e. the critical rate corrected by the factor $\sin \theta / \sin 60^{\circ}$. Thus, 1 Bergeron at the Western Mediterranean latitudes, about $40^{\circ} \mathrm{N}$, corresponds to a deepening rate of $0.7 \mathrm{hPah}^{-1}$ during $24 \mathrm{~h}$. Sanders and Gyakum (1980) concluded that rapid deepenings are more frequent in winter and over strong sea surface temperature gradients, where vigorous changes in the sensible and latent heat fluxes from the sea occur. They also found that surface heating, which produces a weakening of the static stability at lowlevels and favours the convective developments, is also an important contributor to rapid cyclogenesis. The predominant role of the low-levels in the baroclinic developments was also pointed out by Staley and Gall (1977) using a 4 level baroclinic instability analytic model.

Referring to the Mediterranean basin, a climatology over rapidly deepening cyclones was presented by Conte et al. (1997). With a data base of 101 cyclones for the period 1965-1995, they concluded that most of them occured following two fundamental types of development. The first type is characterized by the interaction between a baroclinic open long wave and a short unstable wave at low-levels, usually initiated through orographic forcing. The second type of development results from the interaction of an African subsynoptic low and a middle latitude synoptic depression at the surface. They note the special role of the baroclinicity related to the intense thermal contrast between the two systems. The study shows that more than $60 \%$ of the rapidly developing cyclones over the Mediterranean are classified in the first type and $30 \%$ in the second, with about $10 \%$ not classifiable in any of the two described types. Conte et al. (1997) also refers to a calendar of the cyclones which includes the present case study (22 December 1979), which is not classified in any of the aforementioned two most typical types and it is described as a "sudden development of a depression of African origin".

The aim of this study is to analyse the role of the factors identified in the aforementioned climatological studies to favour very quick cyclogenesis on the Western Mediterranean event of December 1979. The evolution of the surface pressure observations as recorded at the Palma de Mallorca station is analysed. Data from the ECMWF reanalysis are used for a synoptic diagnosis of the event. A qualitative assessment of the upper-level influence through the interpretation of the PV field is also done. Furthermore, numerical experiments are performed using the HIRLAM model. The output fields from the model, with better spatial and temporal resolution than the analyses, are used for a quantitative diagnosis of the baroclinic environment. Moreover, the sensitivity of the cyclogenesis and evolution of the system to the sensible heat flux from the surface, the latent heat release and the orography is investigated.

The paper is organized as follows: Section 2 presents the available observations and the synoptic situation as analysed by the ECMWF. Numerical simulations and a diagnosis of the cyclone are presented in Sect. 3. Moreover, the role of surface sensible heat flux and latent heat release, as well as the influence of the orographic ranges surrounding the Western Mediterranean basin on the development is discussed. Conclusions are summarized in Sect. 4, and suggestions for further work are given.

\section{Observations}

Although the episode occurred in 1979, enough observational data can still be used to analyse the situation and diagnose the event using the current computational tools. Figure 2 depicts the surface pressure evolution as recorded by the Instituto Nacional de Meteorología (INM) barograph at Palma de Mallorca, including the period from 12:00 UTC, 17 December to 00:00 UTC, 24 December 1979. A total decrease of nearly $35 \mathrm{hPa}$ in $60 \mathrm{~h}$ was recorded. The lowest pressure at Palma de Mallorca occurred at 21:00 UTC, 21 December, with $990.6 \mathrm{hPa}$. In addition, sustained winds of $10-12 \mathrm{~m} / \mathrm{s}$ were also recorded in Palma de Mallorca 


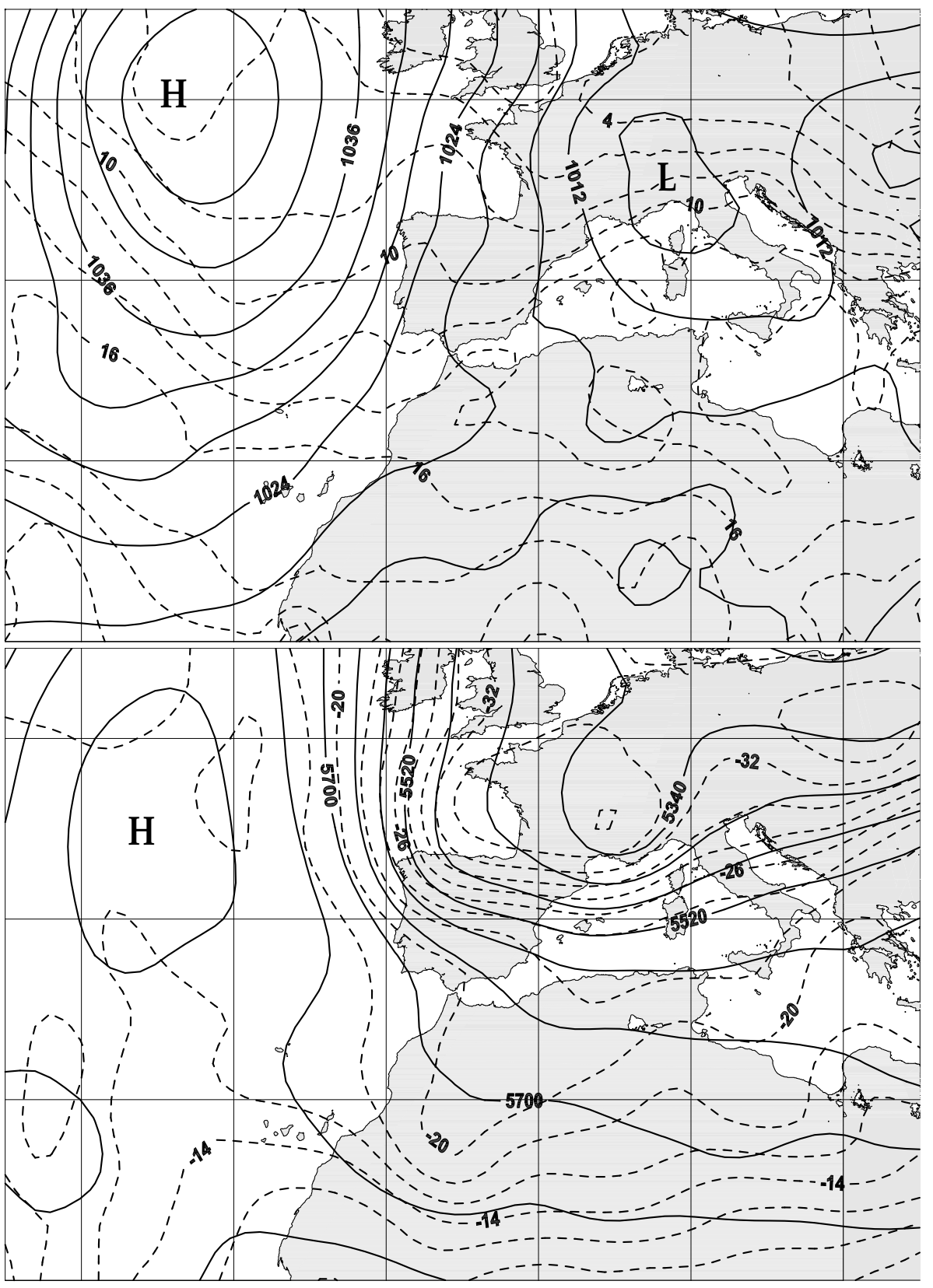

Fig. 3. Synoptic situation from the ECMWF reanalysis at 12:00 UTC, 19December 1979 . (a) Surface pressure ( $\mathrm{hPa}$, solid line) and temperature $\left({ }^{\circ} \mathrm{C}\right.$, dashed line) at $1000 \mathrm{hPa}$, (b) Geopotential height (gpm, continuous line) and temperature $\left({ }^{\circ} \mathrm{C}\right.$, dashed line) at $500 \mathrm{hPa}$. on 21 December, with some gusts exceeding $30 \mathrm{~m} / \mathrm{s}$ in the evening.

Two different periods of strong negative pressure tendency are identified in Fig. 2: the first 12 hours of 19 December and the period from 18:00 UTC, 20 December to 18:00 UTC, 21 December with 1 and $0.7 \mathrm{hPah}^{-1}$ averaged deepenings, respectively. Even though those records do not correspond to the center of the low, both time intervals present tendencies of 1 Bergeron. As it is shown later, these two periods are closely related to two different stages of the synoptic evolution.

ECMWF reanalyses released in 1996 from the T106 spectral model (T106 corresponds to $1.125^{\circ}$ horizontal grid resolution) have been used. Surface pressure, geopotential height, temperature, humidity and wind at 00:00, 06:00, 12:00 and 18:00 UTC were considered.

The synoptic situation at 12:00 UTC, 19 December (Fig. 3a) at low-levels was characterized by a low over central Europe and the Western Mediterranean, together with an anticyclone to the west of the British Isles. This pressure configuration produced northerly cold advection over Western Europe. At mid levels ( $500 \mathrm{hPa}$ in Fig. 3b), a wide trough was present over Europe and the Western Mediterranean with an incipient cold short wave over the northwest Iberian Peninsula. This secondary wave had a notable vorticity nucleus produced by both important curvature and shear. Note the strong temperature and geopotential height gradient belt which covers the Iberian Peninsula, the Western 


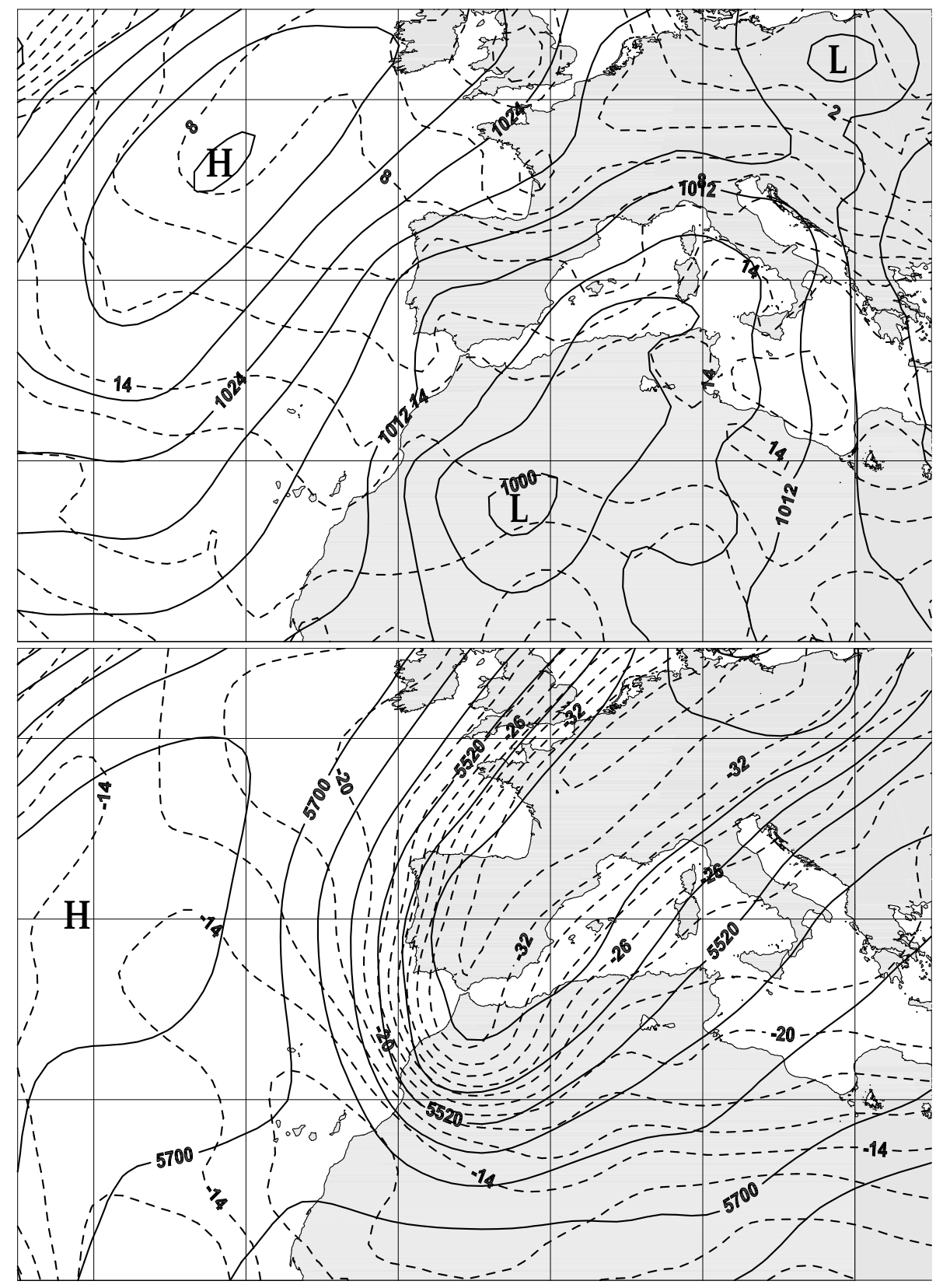

Fig. 4. As in Fig. 3, but at 18:00 UTC, 20 December 1979.
Mediterranean and further east. Strong northerly winds were produced over the British Isles pointing to a notably high curvature region over the Western Iberian Peninsula. This belt is a clear signal of the polar front region.

During the following hours, the previously identified surface low advanced northeastwards, and was still identifiable at 18:00 UTC, 20 December to the top right corner of Fig. 4a. On the other hand, a large-scale surface pressure decrease occurred over the Western Mediterranean and North Africa, with an already identifiable closed center low over continental north Africa with a central pressure lower than $1000 \mathrm{hPa}$. The effect of the low identified in Fig. 3a and the large-scale pressure decrease is reflected in the first period of deepening recorded at Palma de Mallorca, shown in
Fig. 2. At mid levels, the evolution of the aforementioned secondary wave resulted in its enlargement southwards to North Africa (Fig. 4b). The upper-level wave amplified and shortened its wavelength, taking the polar front to unusually southern latitudes. This prominent development at mid and high levels induced the decrease in surface pressure (Fig. 4a) through the classical forcing associated with positive vorticity advection. Figure 5a shows an elongated area of high values of positive relative vorticity, and the forcing term of the quasi-geostrophic omega equation expressed in terms of the $\boldsymbol{Q}$-vector $\left(-2 \nabla_{p} \cdot \boldsymbol{Q}\right)$ at $400 \mathrm{hPa}$ (Holton, 1992, p. 172). Upward motion above the surface low center can be deduced from the positive values of forcing presented in Fig. 5b. This dynamic forcing, labeled as A in Fig. 5b, is positive through- 

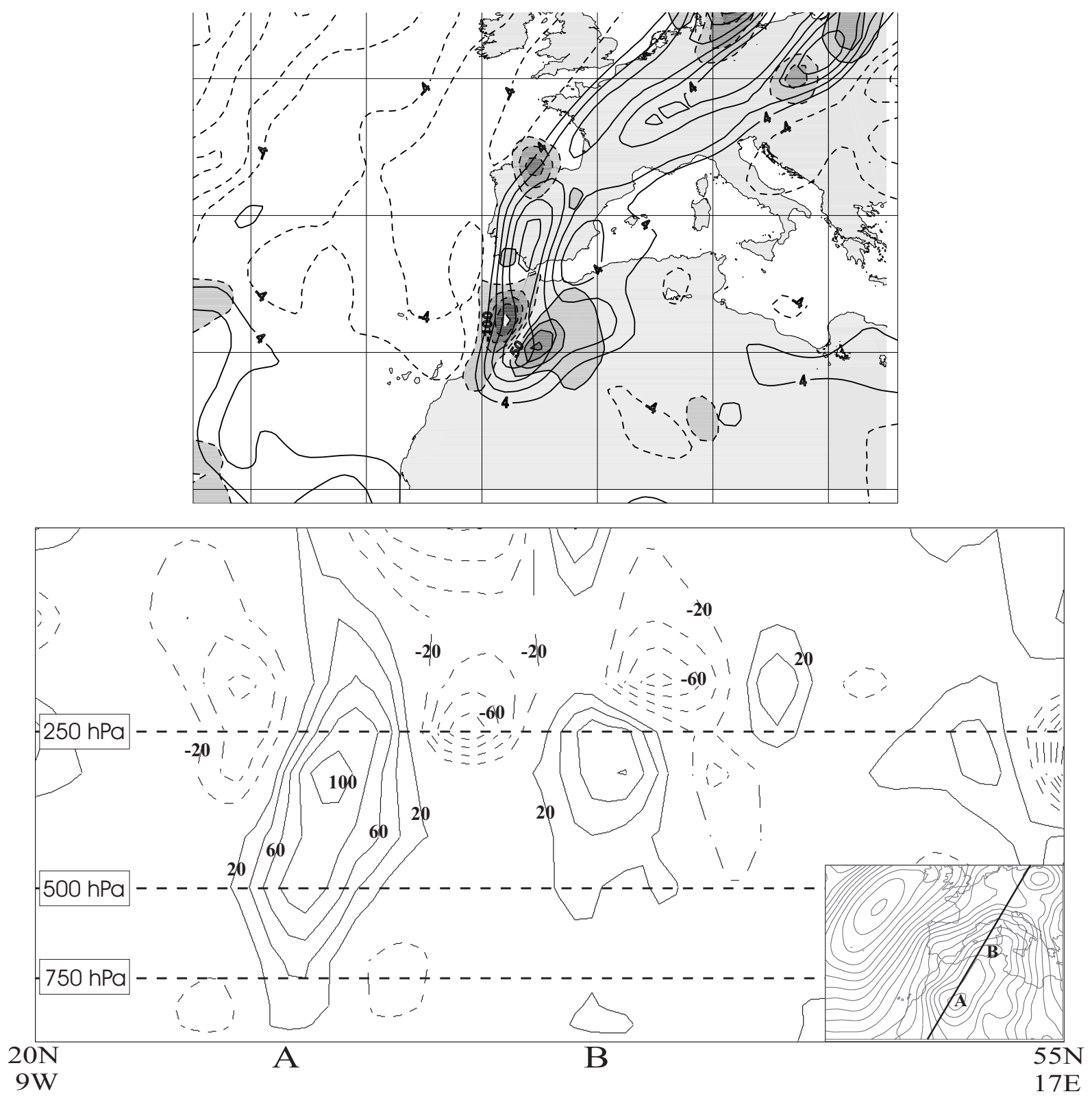

Fig. 5. (a) Relative vorticity $\left(10^{-5} \mathrm{~s}^{-1}\right.$, non-shaded contours) and $\boldsymbol{Q}$-vector forcing, $-2 \nabla_{p} \cdot \boldsymbol{Q}$, of the quasi-geostrophic omega equation $\left(10^{-18} \mathrm{~m} \mathrm{~kg}^{-1} \mathrm{~s}^{-1}\right.$, shaded contours) at $400 \mathrm{hPa}$; and (b) Vertical cross section along the line depicted in the right bottom map, showing the $Q$-vector forcing of the quasi-geostrophic omega equation $\left(10^{-18} \mathrm{~m} \mathrm{~kg}^{-1} \mathrm{~s}^{-1}\right)$. A and B locations are indicated in the map for reference. These fields are diagnosed from ECMWF reanalysis at 18:00 UTC, 20 December 1979. Dashed lines indicate negative values in both panels.

out the troposphere with maximum values at $300 \mathrm{hPa}$, close to the southern strong vorticity nucleus associated with the upper-level short wave identified in Fig. $4 \mathrm{~b}$ and shown in Fig. 5a. During the following hours, cold air from the north was advected towards a warm air pool over North Africa at low-levels. Thus, a strong baroclinic scenario, favouring the deepening of the low was generated.

Figure 6 shows the evolution of the cyclone center from the first time it was clearly identified over Africa (18:00 UTC, 20 December) to 18:00 UTC, 22 December. During the first and last hours of this period, the system was weak and the location of the low center was uncertain but irrelevant. The low moved northeastwards, with a quick advance over land (about $1000 \mathrm{~km}$ in $12 \mathrm{~h}$ ), and a notable speed decrease over the sea (about $500 \mathrm{~km}$ in $12 \mathrm{~h}$ ). The minimum pressure analysed by the ECMWF model was $982 \mathrm{hPa}$, achieved at 00:00 UTC, 22 December, to the east of the Balearics. In fact, the trajectory of the cyclone center in the ECMWF analyses was at its closest point to Palma de Mallorca some time in between 18:00 UTC, 21 December and 00:00 UTC, 22 December. This is in good agreement with the observations at Palma de Mallorca (Fig. 2). This 


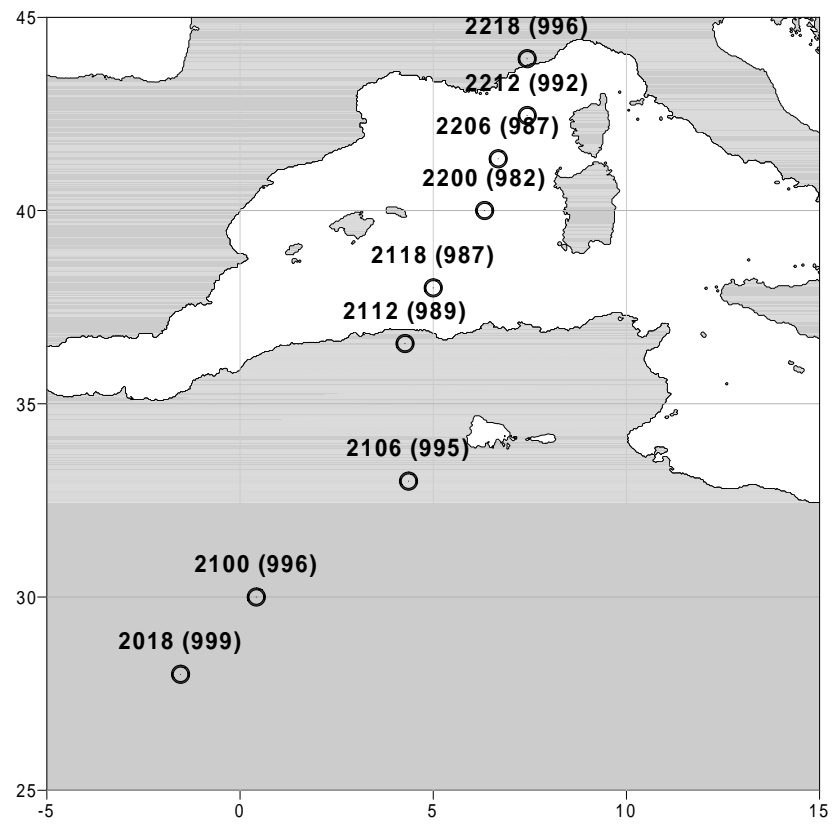

Fig. 6. Position and value of the cyclone central surface pressure $(\mathrm{hPa})$ as located by the ECMWF reanalysis. Labels are presented in DDHH (PPP) format.

northerly movement of the cyclone is reflected as the second period of negative tendency in Fig. 2. In addition, the IR NOAA satellite image (Fig. 7) shows the cyclone center near the North African coastline at 14:00 UTC, 21 December, thus confirming the location of the low given by the analyses. The circular signatures of high clouds around the low center indicate that at high levels, the cyclonic circulation was already closed at 14:00 UTC, 21 December. During its northwards advance, the low acquired a nearly-circular shape (see Fig. 8a for 00:00 UTC, 22 December). The temperature field at lowlevels clearly shows the presence of a warm pool to the east of the low, with a remarkable cold air entrance southwest of the cyclone. This configuration is maintained all along the cyclone trajectory northwards.

At mid levels (Fig. 8b for $500 \mathrm{hPa}$ ), a three nuclei structures developed, with the eastern one associated with the dynamic forcing of low-level deepening. In fact, at 18:00 UTC, 20 December (Fig. 4), the vorticity advection nucleus at mid levels was forcing negative pressure tendencies over the cyclone, whereas at 00:00 UTC, 22 December (Fig. 8), that vorticity nucleus was located rather eastwards of the low-level cyclone center, therefore, not efficiently forcing any further deepening.

\section{Simulations}

Numerical simulations were performed using the short range mesoscale forecasting model HIRLAM (Källén, 1996). The model is formulated on a Latitude-Longitude Arakawa-C grid in the horizontal and a $\mathrm{p}-\sigma$ hybrid staggered profile in the vertical. It explicitly forecasts the surface pressure, hor-

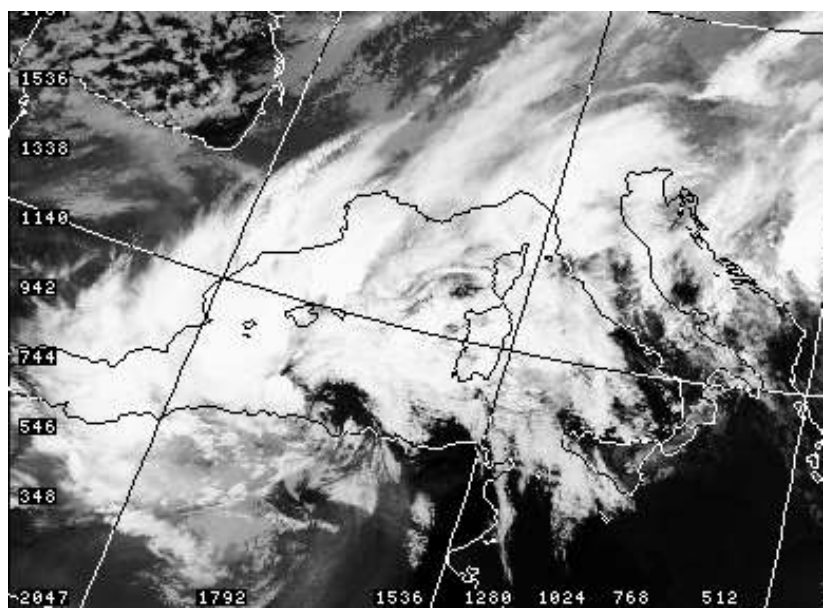

Fig. 7. IR NOAA satellite picture (Channel 4) at 14:00 UTC, 21 December.

izontal wind, temperature, specific humidity and cloud water fields, though several additional derived fields are also obtained from the model. Referring to the parameterizations which directly account for the processes selected for the sensitivity study, vertical turbulent fluxes are parameterized following Louis (1979), accounting for the sensible heat, momentum and moisture fluxes. Surface boundary effects on the atmosphere are calculated by a force-restore model over land, which calculates the temperature and humidity in a 3 layer simplified soil model. A climatic constant sea surface temperature is used over the sea. Condensation and precipitation processes are calculated by the Sundqvist et al. (1989) scheme, which includes large-scale precipitation, convective precipitation (modified Kuo (1974) scheme) and microphysics. The ECMWF reanalysis were used as initial and boundary conditions, which are updated every six hours. A grid of $194 \times 100$ points with $0.3^{\circ}$ (about $30 \mathrm{~km}$ ) was used, covering a domain of about $3600 \times 3300 \mathrm{~km}^{2}$. In the vertical, the same 31 hybrid levels used in the ECMWF model are defined in our simulations.

A first set of simulations was performed in order to obtain higher resolution fields and to better diagnose the mechanisms which produced the cyclone of December 1979. Since the event lasted for more than 5 days and periods longer than 2 days are not reliably simulated by the model, the most interesting simulation intervals have to be selected. The observations from the Palma de Mallorca station showed two periods of intense deepening (Fig. 2). As observed from the ECMWF analyses, the most intense and focused deepening of the cyclone occurred during 21 December (Figs. 6 and 8). Keeping in mind the spin-up time of the model, two simulations were performed to correctly cover the pre-genesis scenario and the cyclone development itself. Thus, a first simulation from 00:00 UTC, 20 December to 00:00 UTC, 22 December (hereafter, C20-22) and a second one from 00:00 UTC, 21 December to 00:00 UTC, 23 December (hereafter, C21-23) were run (Table 1). The C20-22 simulation reveals the character- 


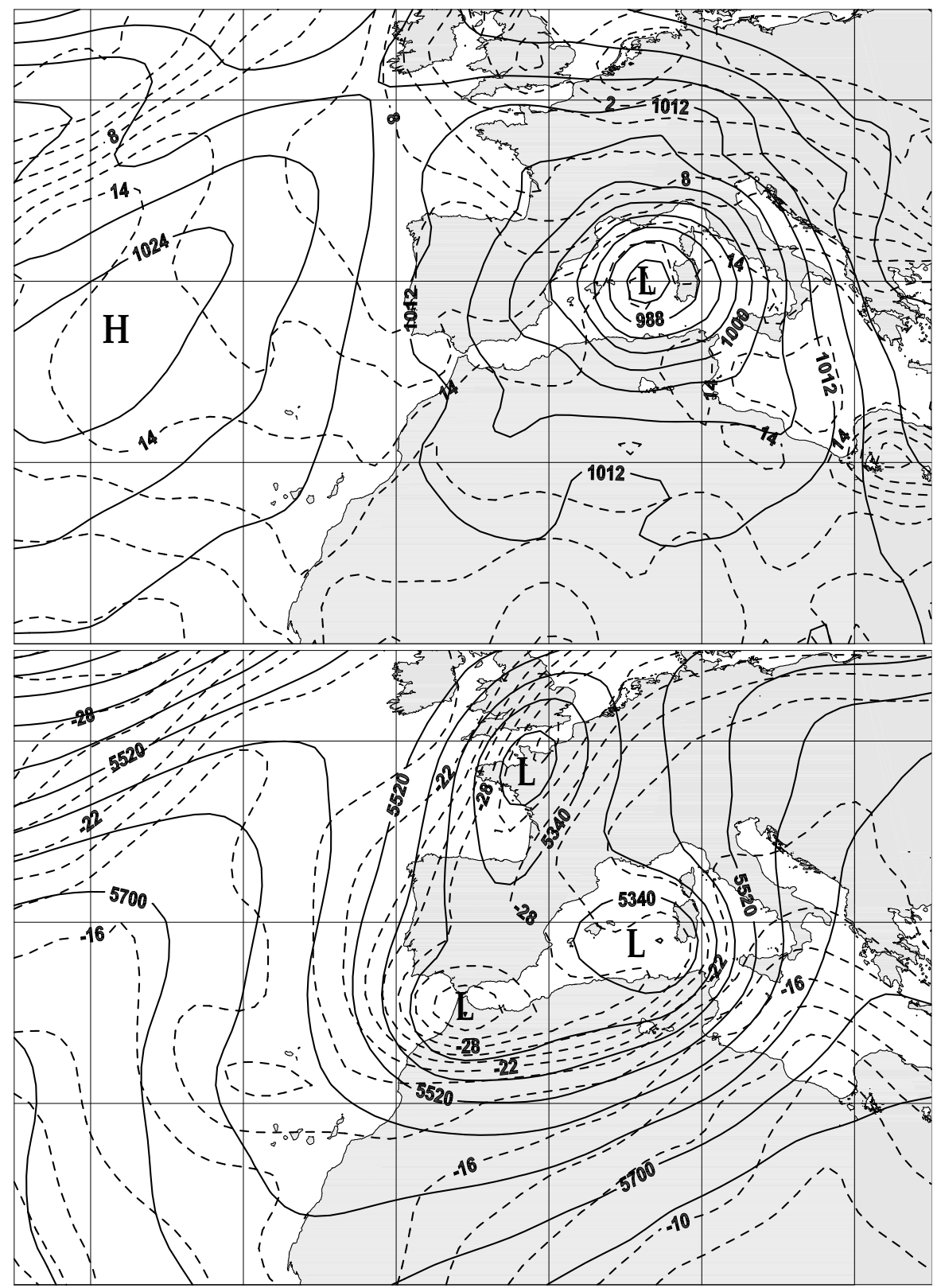

Fig. 8. As in Fig. 3, but at 00:00 UTC, 22 December 1979. istics and the main features of the initial baroclinic scenario better, where strong deepening and northward progression of the low occurred. The C21-23 simulation shows the latter baroclinic evolution, and the trajectory and shape of the cyclone over the Western Mediterranean.

\subsection{Validation runs}

A comparison between the model results and the observations was done in order to assess the accuracy of the model and its derived diagnosis. Figure 9 shows a comparison of the previous data sources and the simulations of the surface pressure at Palma de Mallorca for the complete simulation interval. Both the ECMWF and the simulation values depicted in the graph were obtained by linear interpolation from the 4 nearest gridpoints to the Palma de Mallorca posi- tion. The evolution shown by the ECMWF analyses is similar to that recorded by the INM station, but with a positive shift of about $3 \mathrm{hPa}$, on average, during the deepening period (until 18:00 UTC, 21 December). The ECMWF analyses fits well the actual evolution recorded by the barograph during 22 and 23 December. The positive offset present in the ECMWF analyses during the initial stages of the cyclonic development (i.e. 00:00 UTC, 20 December and 00:00 UTC, 21 December) is introduced to the simulations through the initial conditions. Despite the first 24 hours of C20-22 giving values higher than the observed, the prominent deepening is correctly simulated by the model. However, incorrect values of the surface pressure are obtained during the last hours of C20-22. This error results from the incorrect location of the simulated low center, east of the observed position. 


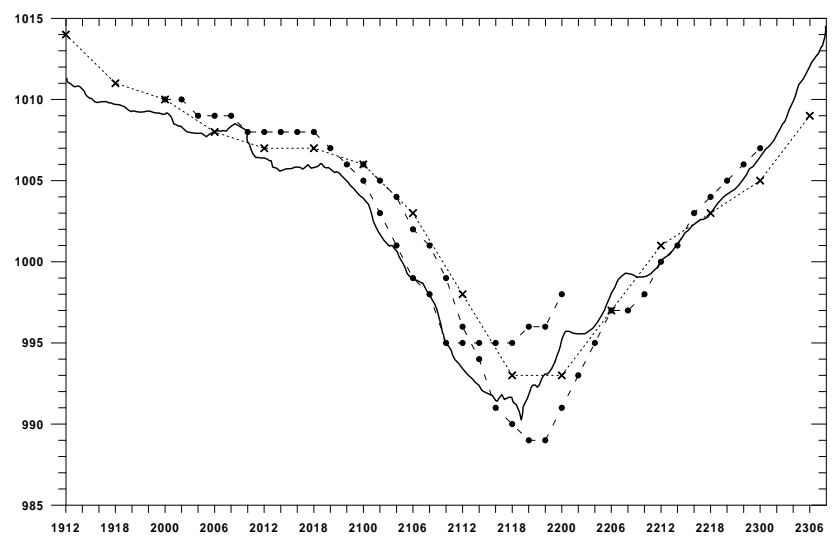

Fig. 9. Evolution of the surface pressure at Palma as recorded by the INM station (strong black line), as analysed by the ECMWF (crosses) and as simulated by the model (filled circles). Two simulations are depicted, C20-22 and C21-23.

On the other hand, $\mathrm{C} 21-23$ starts during the main deepening and so the aforementioned positive offset in the initial conditions is not overcome in the simulation until the last hours of 21 December, when a similar evolution to that recorded at the Palma de Mallorca station is obtained. In fact, the deepest values simulated by $\mathrm{C} 21-23$ at Palma de Mallorca are deeper than the observed ones. Nevertheless, the similarities between the actual and simulated curves at Palma de Mallorca suggest that the model outputs can be trustworthy for a further diagnosis. However, given the $2-3 \mathrm{hPa}$ error margin of the simulated pressure at Palma de Mallorca with respect to the observed, similar uncertainty exists for pressure values over the sea, as inferred from the model.

\subsection{Complete simulation diagnosis}

The scenario at low-levels in which the cyclone deepened was characterized by strong temperature gradients over North Africa, created as a result of the cold air advected from the Atlantic Ocean towards a subtropical air mass over continental North Africa. Figure 10 depicts the fields of geopotential height and temperature at $925 \mathrm{hPa}$ at 00:00 UTC, 21 December for the $\mathrm{C} 20-22$ simulation. It shows a notable temperature gradient belt over North Africa, enhanced by the cyclone through the induced cold advection. This temperature advection at low-levels, together without significant advection at mid levels favours baroclinic instability, which has been described as a major triggering mechanism for the strong deepening of rapid developing lows (Sanders and Gyakum, 1980). Looking for a simple quantitative evaluation of the environmental baroclinicity qualitatively observed in Fig. 10, the e-folding time for a baroclinic wave was calculated using the one layer Eady (1949) linear model. It is based on the simplest baroclinic instability solution, obtained using a continuous linear vertical wind profile over a background state with a zonal flow, and a normal-mode growth is assumed. By using this model, no hypothesis of the physical character of the instability is assumed, but a simple measure of the baroclinicity is obtained. In fact, by taking into account the high-amplitude upper-level trough observed in Fig. 4b, non-normal growth modes are even more probable in this baroclinic scenario. For normal or non-modal growth, the time scale of the instability is given by the vertical shear, and the e-folding time obtained with the Eady model will give a significant measure of this time scale. The e-folding time $\left(t_{e}\right)$ for the most unstable wave was calculated using the expression derived following the development of Haltiner and Williams (1979):

$$
\begin{aligned}
t_{e} & =\frac{\Gamma^{1 / 2}}{0.31 f_{o}\left|\partial_{Z} \boldsymbol{V}\right|} \\
\Gamma & =\frac{H^{2} g}{\bar{T}}\left(\frac{g}{c_{p}}+\frac{1}{H} \partial_{Z} T\right)
\end{aligned}
$$

where $\boldsymbol{V}$ is the horizontal wind, $f_{o}$ is the Coriolis parameter, $\Gamma$ is a stability parameter, $H$ is the scale height (taken as $8 \mathrm{~km}), g$ is the gravity, $c_{p}$ is the specific heat of dry air at constant pressure, $\mathrm{T}$ is the temperature, $\bar{T}$ is a mean vertical temperature and $Z=\ln \left(p / p_{0}\right)$ is the vertical coordinate.

In this case, it has been applied to the $1000-300 \mathrm{hPa}$ layer using a linear shear between the actual winds at the top and bottom boundaries. It is notable that the lowest e-folding times for the normal modes associated with the system appear all along the trajectory followed by the cyclone, in particular, over continental North Africa and to the north of the Atlas Mountains (Fig. 11). Minimum values of less than $25 \mathrm{~h}$ correspond quite well to the $24 \mathrm{~h}$ duration of the second period of intense deepening observed in Fig. 2. Arising from this, the baroclinic growth seems to be a relevant mechanism for the focused deepening of the cyclone.

Moreover, the ECMWF analyses at mid levels, presented in Figs. 4 and 8, show the development of the trough which is affecting the movement and the deepening of the surface cyclone. An overview of the PV field facilitates the explicit visualization and interpretation of the direct influence of the upper-levels on the baroclinic instability evolution. Figure 12 shows the PV field at $250 \mathrm{hPa}$ as derived from the C2123 simulation. At 12:00 UTC, 21 December (Fig. 12a), an anomaly with values higher than 9 PVU is observed to the south of the Iberian Peninsula, west of the surface low center. The circulation associated with the trough produced positive PV advection above the surface cyclone (Fig. 12b), therefore inducing further pressure deepening at low levels. Six hours later, the PV anomaly had been advected eastwards, following the cyclonic flow associated with the main trough and started to overlap the low-level cyclone, which was a less efficient configuration for a further development of the low. In fact, at 00:00 UTC, 22 December (Fig. 12c), the anomaly completely overlapped the surface low and the mutual interaction was not relevant. Later, there was no significant effect of the upper-levels on the deepening and driving of the surface low. This agrees with the analyses from the ECMWF, with the lowest pressure obtained at 00:00 UTC, 22 December in between the Balearic Islands and Corsica. 

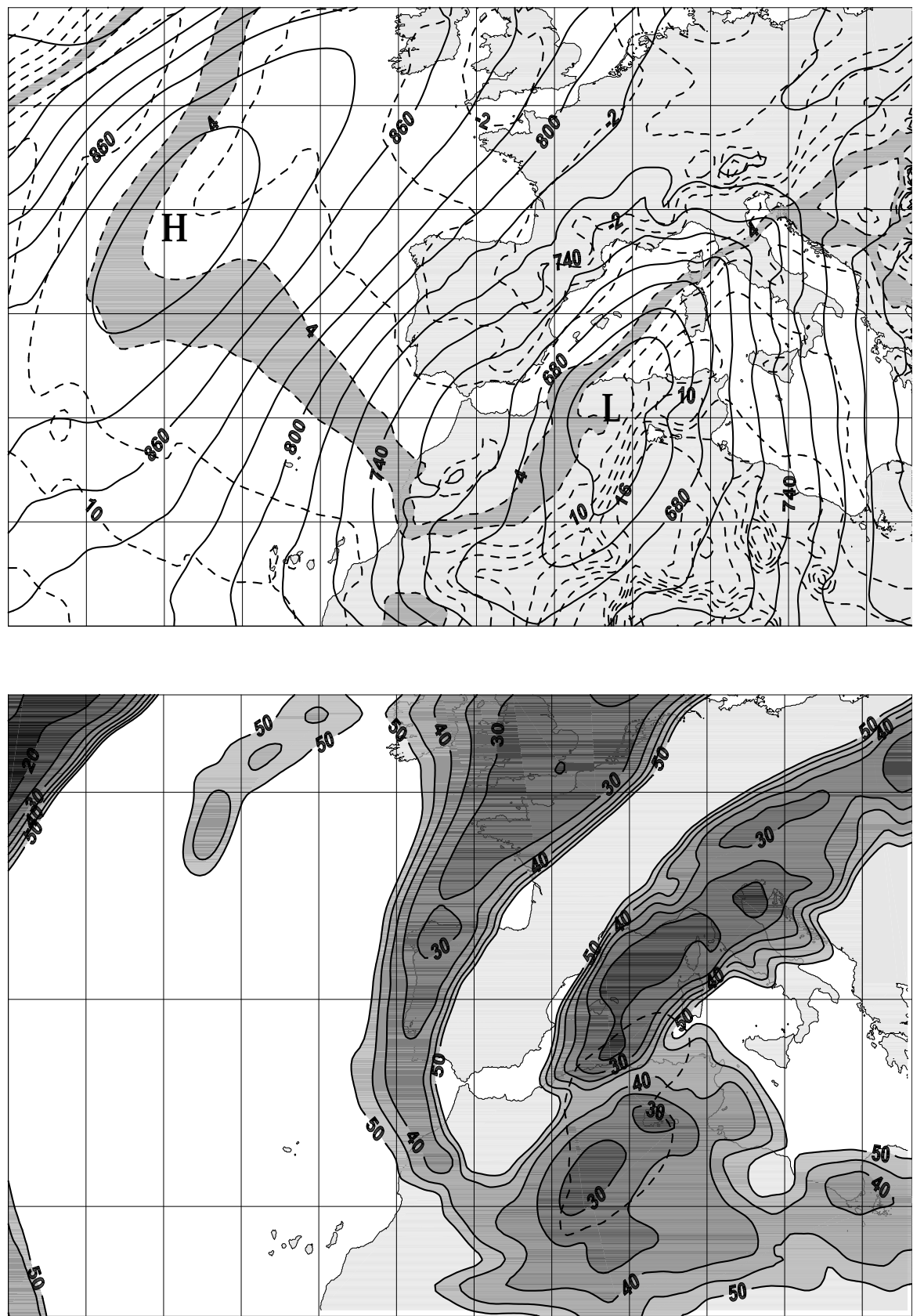

Fig. 10. C20-22 simulation. Geopotential height (solid line, $\Delta=20 \mathrm{gpm}$ ) and temperature (dashed line, $\Delta=2{ }^{\circ} \mathrm{C}$ ) fields at $925 \mathrm{hPa}$, at 00:00 UTC, 21 December $(T+24 h)$. Shaded region corresponds to temperatures between $4^{\circ} \mathrm{C}$ and $6{ }^{\circ} \mathrm{C}$
Fig. 11. C20-22 Simulation. efolding time (hours) shorter than $50 \mathrm{~h}$ for the most unstable wave, as diagnosed by the linear shear baroclinic instability Eady model for 00:00 UTC, 21 December $(\mathrm{T}+24)$. Dashed line depicts the $1000 \mathrm{hPa}$ isobar surrounding the low center.
Regarding the vertical structure of the anomaly, a vertical section of PV and potential temperature across the low reveals a wide tropopause fold associated with the upper-level trough (Fig. 13). The tropopause is clearly identified by an inspection of the vertical gradient of potential temperature. The two southern closed centers previously observed in the geopotential height fields at mid levels (see Fig. 8b) are easily identifiable at $10^{\circ} \mathrm{W}$ and $6^{\circ} \mathrm{E}$ in the PV field. Note that, the general cold anomaly below and warm anomaly above the tropopause fold, as described by Hoskins et al. (1985), is also observed on a smaller scale in the region of the eastern intrusion. A similar situation with a lowered tropopause, a cold troposphere and a warm anomaly in the stratosphere was also described by Wirth and Egger (1999), in a study of a particular case of a cutoff low over the Western Mediterranean. The warm column associated with the eastern intrusion corresponds to the center of the low and shows the warm core of the cyclone. Smaller scale lows over the Western Mediterranean were previously identified by Delorme (1997) as warm core cyclones.

\subsection{No sensible heat flux and no latent heat release simula- tions}

The significant role of the heat fluxes on the cyclogenesis of deep cyclones was pointed out by Sanders and Gyakum (1980). The heating at low-levels from the surface can 


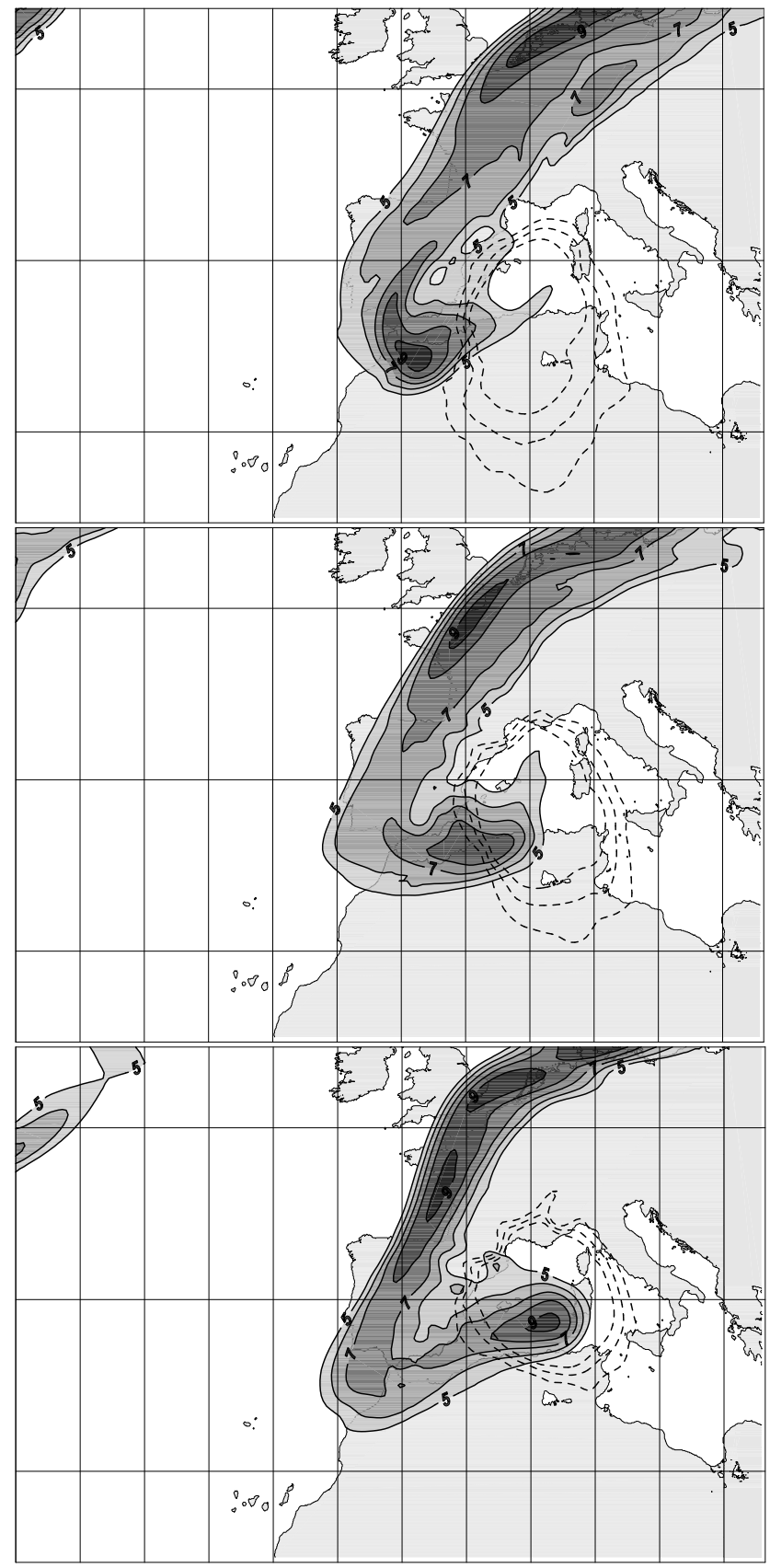

Fig. 12. C21-23 Simulation. Potential vorticity (PVU, 1PVU $=10^{-6} \mathrm{~m}^{2} \mathrm{~s}^{-1} \mathrm{~K} \mathrm{~kg}^{-1}$ ) greater than $5 \mathrm{PVU}$ at $250 \mathrm{hPa}$ for (a) 12:00 UTC, 21 December, (b) 18:00 UTC, 21 December and (c) 00:00 UTC, 22 December. Dashed lines represent 999, 1000 and $1001 \mathrm{hPa}$ surface pressure isolines surrounding the low center.

substantially modify the temperature field, thereby enhancing or destroying the baroclinic environment. On the other hand, the latent heat release, derived from the condensation throughout the troposphere, can be a crucial factor for the vertical extent of the intense deepening.

Four different numerical experiments were performed to study the influence of the aforementioned heat fluxes on the evolution of the cyclone (Table 1): two simulations with the
Table 1. Description of numerical experiments. Dates are given in HH/DD of December 1979 and correspond to initial and ending times of the experiments

\begin{tabular}{ll}
\hline Experiment & Description \\
\hline C20-22 & Control Run $(00 / 20$ to 00/22) \\
C21-23 & Control Run (00/21 to 00/23) \\
NSH20-22 & No Sensible Heat Run $(00 / 20$ to 00/22) \\
NSH21-23 & No Sensible Heat Run (00/21 to 00/23) \\
NLH20-22 & No Latent Heat Run (00/20 to 00/22) \\
NLH21-23 & No Latent Heat Run (00/21 to 00/23) \\
NT21-23 & No Topography Run $(00 / 21$ to 00/23) \\
\hline
\end{tabular}

same configuration as the complete experiments but without sensible heat flux from the surface (hereafter, experiments NSH20-22 and NSH21-23) and another two, also with the same configuration as the complete runs but without condensation processes (hereafter, experiments NLH20-22 and NLH21-23). The NLH experiments keep all the surface processes on but essentially do not release latent heat from the condensation to the environment.

The evolution of the central pressure of the cyclone, as simulated by C21-23, NSH21-23 and NLH21-23, is depicted in Fig. 14. A first conclusion regarding sensible heat flux is that its influence on the low development during the period of simulation is negligible. This result reveals that the warm pool over North Africa was already contained in the initial conditions. Then, together with the cold advection from the Atlantic, the model reproduced the development of the cyclone with no significant influence from the sensible heat flux. The results from the NSH20-22 simulation (not shown) present the same behavior during the initial stages of the low.

On the contrary, referring to the latent heat release, the NLH21-23 experiment simulates a central surface pressure notably higher than C21-23, therefore attributing an important cyclogenetic role to the release of latent heat from the condensation processes. In fact, a difference of $7 \mathrm{hPa}$ in the central pressure is obtained between the two simulations during the maximum depth for the C21-23. This influence of the latent heat release on the central pressure represents $44 \%$ of the deepening obtained for the whole integration period. For the NLH20-22 simulation (not shown), a cyclogenetic effect is also attributed to the latent heat release, but with weaker differences than for the 21-23 period. An explicit effect of the latent heat release, in this case, indirectly reflected in Fig. 14 for the central surface pressure, can be observed through the potential temperature field. Figure 15 shows a vertical section across the surface low, revealing a PV structure at the tropopause for the NLS21-23 similar to that obtained for the CS21-23 (Fig. 13). However, a notable difference appears in the potential temperature distribution below the wide tropopause fold. In the NLH21-23 experiment, no warm column over the center of the low appears. It re- 


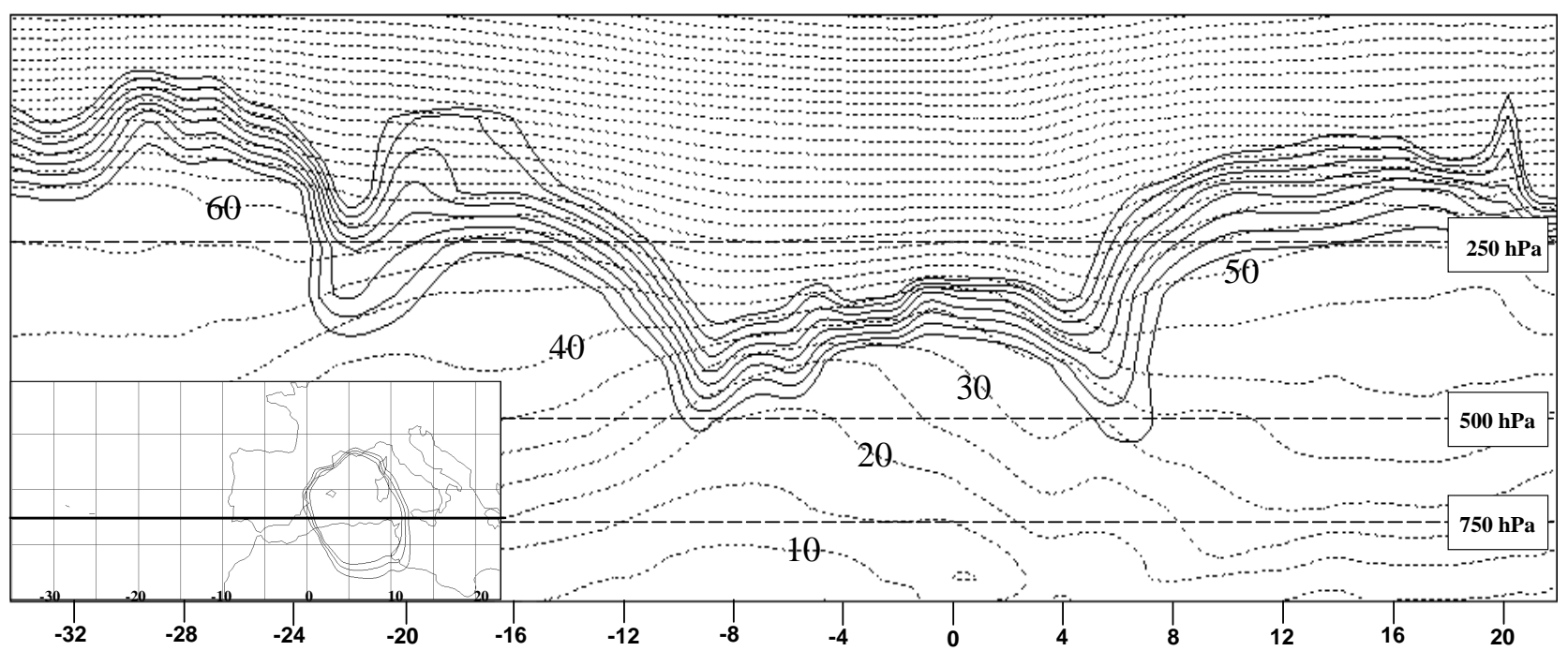

Fig. 13. C21-23 simulated PV (solid lines, PVU) and potential temperature (dashed lines, ${ }^{\circ} \mathrm{C}$ ) vertical section across the cyclone at 18:00 UTC, 21 December. PV isolines from 1.5 PVU to 5 PVU with a 0.5 PVU interval. Potential temperature isolines depicted with a $5{ }^{\circ} \mathrm{C}$ interval. Left bottom map shows the vertical section position relative to the cyclone.

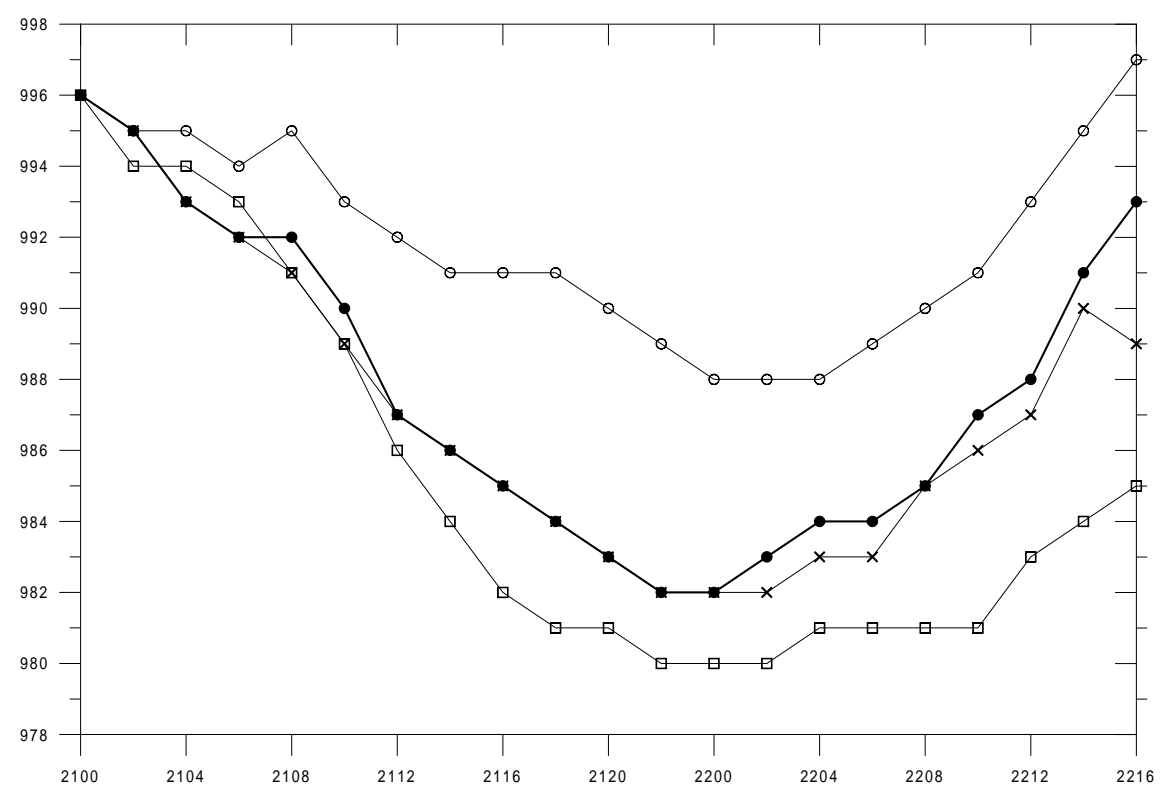

Fig. 14. Central surface pressure $(\mathrm{hPa})$ for the cyclone as simulated by the C21-23 (filled circles), NT21-23 (squares), NSH21-23 (crosses) and NLH21-23 (empty circles) simulations for the period from 00:00 UTC, 21 December to 16:00 UTC, 22 December 1979. Date labels are presented in DDHH format.

sults in a wider cold area below the fold, without the warm core westwards of the eastern deeper PV intrusion. Thus, the warm core described in Fig. 13 is produced by latent heat release from the cloud systems surrounding the low center, previously observed on the NOAA satellite image (Fig. 7).

\subsection{Non-orographic simulation}

The orography plays a crucial role in the cyclogenetic processes over the Western Mediterranean basin. The role of the Alps and Atlas Mountains interacting with the midtropospheric flow has been described to a large extent (e.g. Reiter, 1975). The Alps range is described as a cyclogenetic agent, by inducing the Alpine lee cyclogenesis when interacting with cold fronts associated with Atlantic cyclones (Buzzi and Tibaldi, 1978). This cyclogenesis can be notably deep and local, favouring the development of strong winds and severe weather in the area. On the other hand, the interaction of the African Atlas Mountains with the mid-level southerly flows produces a shallow cyclone at low-levels to the north of the range. This lee cyclogenesis, though usually weak, is described as crucial in some episodes of heavy rainfall in Eastern Spain (Romero et al., 1997; Homar et al., 1999). Thus, the ranges surrounding the Western Mediterranean basin might have had an important influence, likely cyclonic, on the evolution of the cyclone of December 1979.

The analysis of the orographic role on the evolution of this 


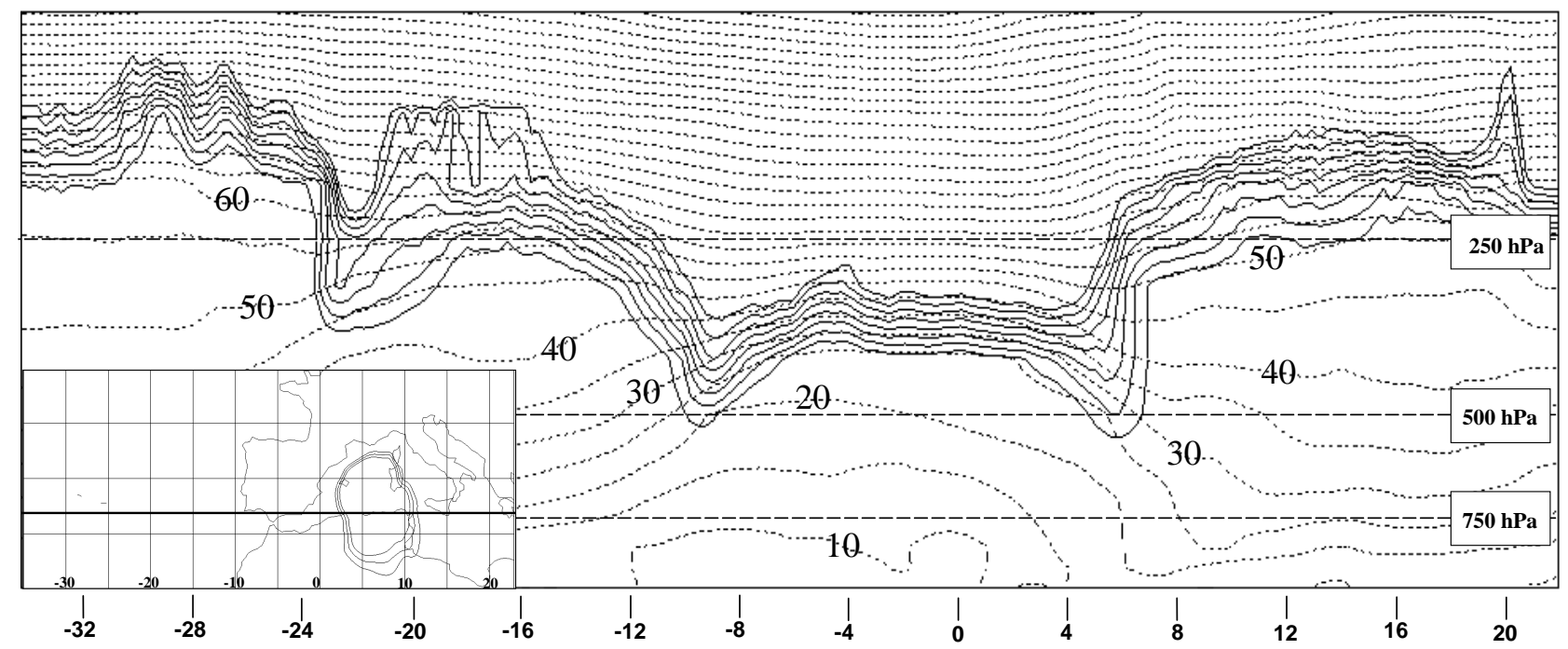

Fig. 15. NLH21-23 simulated PV (solid lines, PVU) and potential temperature (dashed lines, ${ }^{\circ} \mathrm{C}$ ) vertical section across the cyclone at 18:00 UTC, 21 December. PV isolines start at $1.5 \mathrm{PVU}$ with a $0.5 \mathrm{PVU}$ interval. Potential temperature isolines depicted with a $5^{\circ} \mathrm{C}$ interval. Left bottom map shows the vertical section position relative to the cyclone.

cyclone, which was generated out of the Mediterranean basin and it later moved into the area, is important since lee cyclogenesis events are usually studied in the basin. The effect of the orography on the trajectory and deepening of the cyclone was analysed by performing a simulation from 00:00 UTC, 21 December to 00:00 UTC, 23 December using flat topography over land (hereafter, NT21-23). This experiment contains no information on the orographic systems height except that which was introduced through the initial and lateral boundary conditions.

Figure 14 depicts the evolution of the surface central pressure of the low, as simulated by the NT21-23 experiment. The simulations C21-23 and NT21-23 are quite similar during the first 12 hours, while the low center remains over Africa. From this time, NT21-23 simulates an evolution with lower pressures than C21-23, though very similar timing is obtained. The lowest pressure obtained in NT21-23, $980 \mathrm{hPa}$, occurred during last hours of 21 December and first hours of 22 December. The $2 \mathrm{hPa}$ difference between the two simulations is quantitatively insignificant, although it contributes a weak, but cyclolytic role to the orography of this event.

Regarding the location of the low center, Fig. 16 presents the trajectory of both the C21-23 and NT21-23 simulations. A first analysis reveals that both trajectories are similar, although the non-orographic simulated cyclone evolves westwards of the complete simulation one. This shifting eastwards produced by the orography may be explained by the action of the African Atlas, interacting with the cyclonic circulation, in a similar way as the redirection southwards was produced by the Rocky Mountains in the United States on the eastward progressing cyclones from the Pacific (e.g. Bluestein, 1993). Moreover, an additional simulation with flat African orography (not presented) does not show this eastward shifting, thus confirming the crucial role of the Atlas Mountains. On the other hand, the cyclolytic effect derived from NT21-23 results is explained by a "wall effect" induced by the Pyrenees, Central Massif and Western Alps. This effect is produced by both the action of the orographically induced pressure dipoles, which substantially modifies the low-level circulation, and the mountain drag, which becomes more effective as the strong winds located close to the low center approach the ranges. Figure 17 depicts the central region of the cyclone as simulated by $\mathrm{C} 21-23$ and NT21-23 for the period from 06:00 UTC, 21 December to 06:00 UTC, 22 December. The role of the different mountainous ranges on the surface pressure field clearly become more notable as the low approaches the northern orographic systems. At 06:00 UTC, 21 December (Fig. 17a), both simulations are very similar, with weak flow impinging to the Atlas. On 21 December, the low advanced northwards and a slight influence of the northern mountains of the basin on the CS21-23 surface pressure is detected (Fig. 17b). Later, at 06:00 UTC, 22 December, the Pyrenees induce a clear relative high to its north, which is reflected in Fig. 17c with anticyclonic curvature. The Central Massif and Alps also induce significant relative highs. The consequence of the high pressure poles was to restrict the advancing and enlargement of the main low towards those systems. The cyclonic flow itself enhanced those dipoles by interacting with the northern ranges of the basin. Thus, the deeper and closer to the ranges the cyclone was, the stronger the winds were and the more effectively the windward orographic high pressure center was induced. Moreover, this enhancement of the wind speed also produces an increase in the mountain drag effect. This mechanism is clearly identified over the Pyrenees in Fig. 17 and it was also present over the Alps and Central Massif. On the other hand, the relative low pressure poles of the orographic 


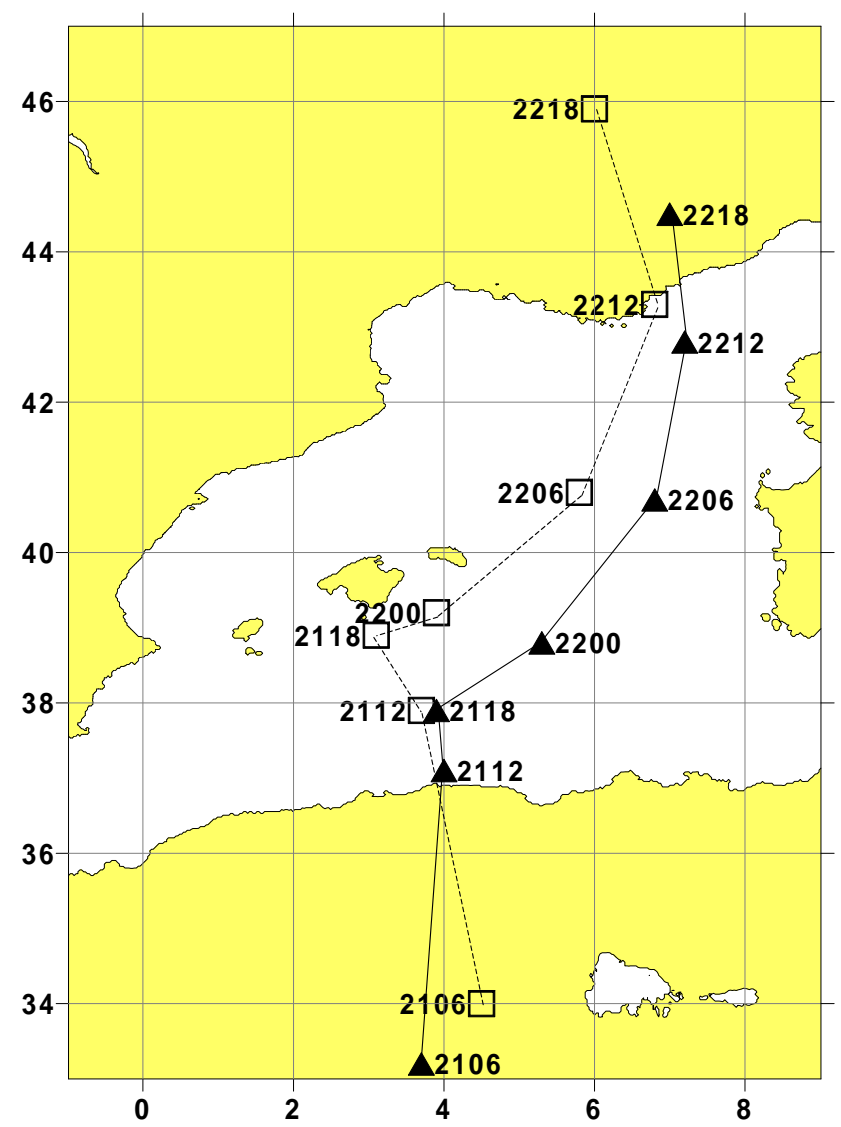

Fig. 16. Position of the cyclone centre as simulated by the $\mathrm{C} 21-$ 23 (triangles) and NT21-23 (squares) experiments. Date labels are presented in DDHH format.

dipoles are also identified in Fig. 17. This local increase in the cyclonic circulation to the lee of the mountains was less influential for a further flow modification, since no effect on the latter impinging flow which governs the orographic dipole intensity is derived.

\section{Conclusions}

A first exploratory study of an African cyclone occurred from 19 to 22 December 1979, which moved northwards towards the Western Mediterranean, has been presented. The quick African deepening and the northwards trajectory makes it an unusual cyclone in the area. Barometer records from Palma de Mallorca present a nearly continuous decreasing of the surface pressure, about $35 \mathrm{hPa}$ in $60 \mathrm{~h}$, with minimum recorded pressure of $990.6 \mathrm{hPa}$. Simple calculations have revealed that the deepening of the cyclone exceeded 1 Bergeron, fulfilling the quickly deepened cyclone definition of Sanders and Gyakum (1980). The ECMWF analyses show an unusually rapid deepening low at quite low latitudes, formed over North Africa. The cyclone moved northwards and achieved its maximum depth during the night of 21 December, east of the Iberian Peninsula. The synoptic situation in which the

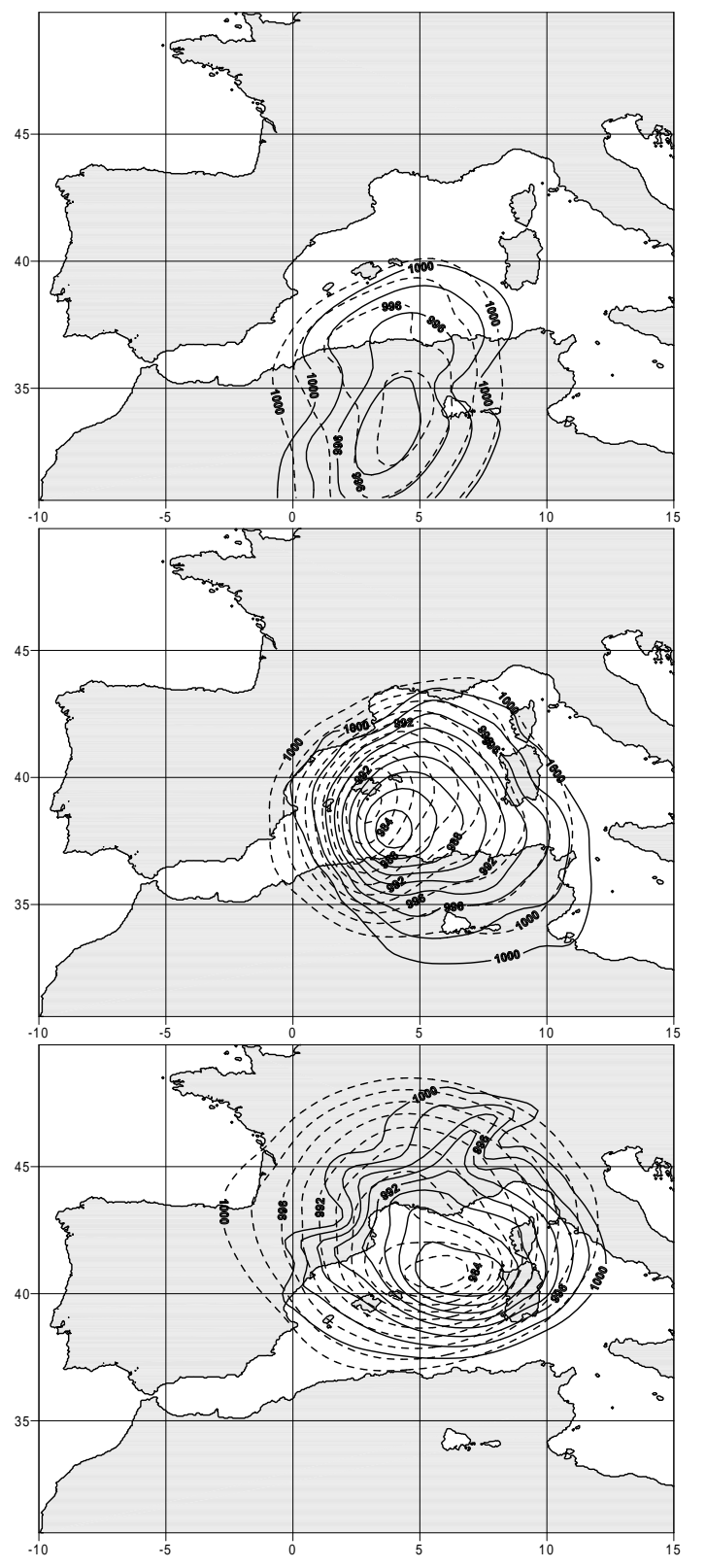

Fig. 17. Surface pressure (hPa) lower than $1000 \mathrm{hPa}$ as simulated by C21-23 (solid lines) and NT21-23 (dashed lines) at (a) 06:00 UTC, 21 December, (b) 18:00 UTC, 21 December and (c) 06:00 UTC, 22 December.

cyclone developed was characterized by a prominent midand high-tropospheric trough which resulted in an unusually southern location of the polar front. A wide area with low surface pressure values over the Western Mediterranean is observed before the cyclone development, mainly related to the evolution of the upper-level trough. A synoptic signature for upward motion is found around the cyclone center location, associated with the upper-level trough. Numerical simulations revealed some significant subsynoptic structures which contributed to the development and evolution of the extraordinary cyclone. The cyclogenesis occurred in a 
baroclinic environment over North Africa, caused by strong cold advection from the northwest towards a warm air mass, enhanced by both a synoptic high over the Atlantic and a cyclone over Europe. Simple calculations using a linear normal-mode baroclinic growth model reveals a significant role of the baroclinic instability, by reproducing the location and growth rate of the cyclone. No firm conclusions on the character of the instability are obtained, but the presence of an intense PV streamer at upper-levels suggests the non-modal growth as the most probable. In fact, the analysis of the PV field reveals that the advection of upper-level PV anomalies was an important mechanism for the surface pressure deepening forcing. A wide tropopause fold was identified over the cyclone with two deeper intrusions to its east and west sides. Numerical experiments revealed a negligible role of the sensible heat flux from the surface on the cyclogenesis during the simulation periods. Furthermore, a warm core was found in the cyclone, completely attributable to the latent heat release from the condensation processes throughout the troposphere. Finally, the latent heat release was found to contribute with $7 \mathrm{hPa}$ to the minimum observed pressure, nearly $45 \%$ of the total deepening obtained in the simulations on 21 December.

The effect of the orography was assessed through a nonorographic simulation. The main features obtained for the non-orographic cyclone are similar to those obtained with the complete one, confirming the weak action of the orography on this event, and indirectly showing the leading role of the baroclinic instability mechanism, supported by both the low-level cold air advection and the upper-level dynamic evolution. Nevertheless, a mountain drag effect and an unusual cyclolytic effect of the northern mountain ranges of the Mediterranean basin has been presented. The equilibrium which appears windward of the Pyrenees, Alps and Central Massif, between the low pressure associated with the cyclone and the orographically induced high pressure nuclei, became a restrictive mechanism which substantially modified the development of the low. An evaluation of the interaction among the relevant factors identified in this study remains for future studies.

Acknowledgements. The authors thank Dr. R. Romero for his helpful suggestions and the reviewers, which helped make this a significantly better paper. ECMWF meteorological fields were provided by the Instituto Nacional de Meteorología (INM) of Spain. Satellite image was obtained from the Dundee Satellite Receiving Station archive. The HIRLAM System was developed by the HIRLAM Project group, a cooperative project of the national weather services in Denmark, Finland, Iceland, Ireland, the Netherlands, Norway, Spain and Sweden. This work has been partially sponsored by CICYT CLI99-0269 grant.

Topical Editor J.-D. Duvel thanks P. Unden and another referee for their help in evaluating this paper.

\section{References}

Alpert, P., Neeman, B. U., and Shay-El, Y.: Climatological analysis of Mediterranean cyclones using ECMWF data, Tellus, 42A, 6777, 1990.

Bessemoulin, P., Bougeault, P., Genovés, A., Jansà, A., and Puech, D.: Mountain pressure drag during PYREX, Beitr. Phys. Atmosph., 66, 305-325, 1993.

Bluestein, H. B.: Synoptic-Dynamic Meteorology in Midlatitudes. Vol II, Oxford University Pres, Inc., New York, pp. 594, 1993.

Buzzi, A. and Tibaldi, S.: Cyclogenesis in the lee of the Alps: A case study, Q. J. R. Meteorol. Soc., 104, 271-287, 1978.

Conte, M., Piervitali, E., and Colacino, M.: The meteorological "bomb" in the Mediterranean, in: INM/WMO International symposium on cyclones and hazardous weather in the Mediterranean, pp. 283-287, Instituto Nacional de Meteorología, Apartado 285, 28071 Madrid, España, 1997.

Delorme, R.: Warm core storms in the Mediterranean, in: INM/WMO International symposium on cyclones and hazardous weather in the Mediterranean, pp. 255-260, Instituto Nacional de Meteorología, Apartado 285, 28071 Madrid, España, 1997.

Eady, E. T.: Long waves and cyclone waves, Tellus, 1, 3, 33-52, 1949.

Haltiner, G. J. and Williams, R. T.: Numerical prediction and dynamic meteorology, Second Edition, John Wiley \& Sons, New York, 1979.

Holton, J. R.: An introduction to dynamic meteorology, Third Edition, vol. 48 of International Geophysics Series, Academic Press, New York, 1992.

Homar, V., Ramis, C., Romero, R., Alonso, S., García-Moya, J., and Alarcón, M.: A case of convection development over the western Mediterranean sea: A study through numerical simulations, Meteor. Atmos. Phys., 71, 169-188, 1999.

Hoskins, B. J., McIntyre, M. E., and Robertson, A. W.: On the use and significance of isentropic potential vorticity maps, Q. J. R. Meteorol. Soc., 111, 877-946, 1985.

Källén, E.: Hirlam Documentation Manual., Available from SMHI S-60176 Norrkoping, Sweden, 1996.

Kuo, H.: Further studies of the parameterization of the influence of cumulus convection on large-scale flow, J. Atmos. Sci., 31, 1232-1240, 1974.

Louis, J. F.: A parametric model of vertical eddy fluxes in the atmosphere, Bound. Layer Meteor., 17, 187-202, 1979.

Raymond, D. J.: Nonlinear balance and potential-vorticity thinking at large rossby number, Q. J. R. Meteorol. Soc., 118, 987-1015, 1992.

Reiter, E. R.: Handbook for forecasters in the Mediterranean, Naval Postgraduate School, Monterey, California, 1975.

Romero, R., Ramis, C., and Alonso, S.: Numerical simulation of an extreme rainfall event in Catalonia: Role of orography and evaporation from the sea, Q. J. R. Meteorol. Soc., 123, 537-559, 1997.

Sanders, F. and Gyakum, J.: Synoptic-dynamic climatology of the "Bomb", Mon. Wea. Rev., 108, 1589-1606, 1980.

Staley, D. O. and Gall, R. L.: On the wavelength of warm baroclinic instability, J. Atmos. Sci., 34, 1679-1688, 1977.

Sundqvist, H., Berge, E., and Kristánsson, J.: Condensation and cloud parameterization studies with a mesoscale numerical weather prediction model, Mon. Wea. Rev., 117, 1641-1657, 1989.

Wirth, V. and Egger, J.: Diagnosing extratropical synoptic-scale stratosphere-troposphere exchange: A case study, Q. J. R. Meteorol. Soc., 125, 635-655, 1999. 